\title{
A METODOLOGIA DE RESOLUÇÃO DE PROBLEMAS: UMA EXPERIÊNCIA PARA O ESTUDO DAS LIGAÇÕES QUÍMICAS
}

\author{
Franciane S. C. de Lima, Leliz T. Arenas e Camila G. Passos* \\ Departamento de Química Inorgânica, Instituto de Química, Universidade Federal do Rio Grande do Sul, 91501-970 Porto Alegre \\ - RS, Brasil
}

Recebido em 07/08/2017; aceito em 30/11/2017; publicado na web em 20/12/2017

\begin{abstract}
THE PROBLEM SOLVING METHODOLOGY: AN EXPERIENCE FOR THE STUDY OF CHEMICAL BONDS. This article presents an experience of the use of the Problem Solving (PR) methodology with undergraduate students of the Licentiate Course in Chemistry of UFRGS, for the study of Ionic Bonding (LI). Salar de Uyuni salts were used to contextualize the problems employed. The Field Log records of the researchers and the presentations of the undergraduates show that the implemented didactic sequence favored conceptual learning, such as the relation between chemical bond theories and some properties of the materials, procedural learning, such as public argument, as reading and handling of different bibliographical reference sources and attitude learning, such as interpersonal relations among students and teachers during the different problem solving stages. Additionally, the results brought to evidence that, from the Problem Solving experience with the Ionic Bond contents, the future teachers were able to perceive work alternatives for their future classrooms.
\end{abstract}

Keywords: problem solving; teacher formation; chemical bonds; Salar de Uyuni.

\section{INTRODUÇÃO}

O presente artigo apresenta uma experiência da utilização da metodologia de Resolução de Problemas (RP) com licenciandos do curso de Licenciatura em Química da UFRGS, para o estudo de ligações químicas, especificamente, Ligações Iônicas (LI). Esse conteúdo foi escolhido, pois há um pequeno número de relatos na literatura sobre o ensino de ligações químicas a partir de perspectivas investigativas. Além disso, esse tema é importante para o entendimento de outros conteúdos de química e de propriedades da matéria como condutividade elétrica, solubilidade e pontos de fusão e ebulição. ${ }^{1,2}$

De acordo com alguns pesquisadores, devido às dificuldades de compreensão dos conceitos científicos, e, também, falta de domínio do uso de metodologias alternativas ao modelo de ensino tradicional, os professores de Ciências podem afastar seus alunos do mundo científico, pois exigem que os estudantes aprendam pela memorização e não pelo entendimento dos conceitos..$^{3-5}$ Essas práticas podem estar relacionadas às fragilidades na formação inicial, no que se refere à falta de um eixo formativo que possua a função de integrar conhecimentos conceituais da Química às contemporâneas metodologias de ensino. ${ }^{6-8}$ Herreid $^{9}$ destaca que dentre os professores, os de Ciências, Química e Física são os que menos empregam metodologias ativas de aprendizagem.

Nesse âmbito, acredita-se que trabalhar a RP com os licenciandos no papel de alunos pode favorecer que estes se utilizem dessa metodologia nas suas futuras salas de aula com maior propriedade, como apresenta-se no decorrer do texto.

\section{FUNDAMENTAÇÃO TEÓRICA}

\section{Resolução de problemas}

Diversos relatos na literatura apontam que o uso da metodologia de Resolução de Problemas (RP) no ensino de Química, tanto nos contextos de sala de aula, ${ }^{10-13}$ como nos cursos de formação de

*e-mail: camila.passos@ufrgs.br professores, ${ }^{14-16}$ contribui significativamente para a aprendizagem dos estudantes, por envolver alunos e professores na construção do conhecimento científico contextualizado, no uso de seus aportes teóricos e ferramentas tecnológicas.

A RP caracteriza-se por incitar os estudantes a pensar e a criar, logo, é uma estratégia que permite aos sujeitos desenvolver uma ação ativa durante sua educação científica. ${ }^{9}$ Esta perspectiva de aprendizagem é uma das variantes do método Problem Based Learning (PBL). Esse método de ensino foi implantado na década de 1960 na Faculdade de Medicina da Universidade McMaster, Canadá, para superar lacunas formativas quanto à integração de conhecimentos teóricos e práticos e fazer com que os estudantes pudessem ter contato com situações reais de sua futura prática profissional. ${ }^{17}$ Nesse sentido, mostrou-se tão eficiente que foi disseminado para outras universidades e cursos de diferentes áreas do conhecimento. A PBL pode ser utilizada como estratégia didática de uma disciplina, um conjunto de disciplinas ou para fundamentar o currículo de um curso..$^{9,17}$

No ensino de Ciências, passou a ser utilizada na década de $1990 .{ }^{18}$ Atualmente encontram-se trabalhos sobre o uso da PBL relacionados ao aprendizado de determinados conteúdos químicos. ${ }^{9,19}$ Todavia, a maioria dos artigos descreve a utilização do método para o desenvolvimento de habilidades necessárias aos futuros profissionais da Química, ${ }^{9,20-22}$ como uso da linguagem,,${ }^{21}$ consciência cultural num contexto de globalização econômica, ${ }^{22}$ assim como para a aquisição de uma maior consciência ambiental. ${ }^{19}$

Em contrapartida, o uso da RP está mais direcionado à aprendizagem de conhecimentos científicos através da resolução de situações-problema. Nessa perspectiva de aprendizagem, um problema é entendido como uma situação que apresenta certo nível de dificuldade e para o qual não se tem de imediato uma solução. ${ }^{10,15}$ Dessa forma, para resolver um problema, se requer a utilização de determinados procedimentos que envolvem processos intelectuais, motivacionais e operatórios semelhantes aos processos seguidos em uma investigação científica. ${ }^{13}$ Os princípios da estratégia da RP contemplam atividades multifacetadas que integram pequenas investigações práticas ou em campo, com os conteúdos conceituais e os exercícios de lápis e papel. ${ }^{5,13}$ 
Os trabalhos do grupo de Daniel Gil-Pérez e outros investigadores da Universidade de Valência são pioneiros na utilização da RP desde a década de 1980 para o ensino de Ciências, ${ }^{23}$ na Educação Básica, ${ }^{10}$ na Educação Superior ${ }^{15}$ e na formação de professores. ${ }^{16}$

Em especial para a formação de professores, os autores apontam que a RP pode contribuir para a transformação dos sistemas de educação universitária, pois é uma metodologia interativa, que visa o maior envolvimento e a autonomia dos estudantes no processo de ensino-aprendizagem. Dessa forma, os futuros professores, a partir de ações formativas que estimulem o caráter social e coletivo da investigação científica, poderão desenvolver conhecimentos científicos e profissionais de forma ativa e integrada. ${ }^{15,16}$ Como consequência, inovações pedagógicas são esperadas para suas futuras práticas profissionais.

Desde então, pesquisadores buscam compreender quais as dificuldades dos estudantes ao resolverem problemas, ${ }^{13,23,24}$ quais as modelagens utilizadas pelos alunos para resolverem as situações-problema ${ }^{16,25}$ e quais as possíveis estratégias para o uso da resolução dos problemas. ${ }^{15,26}$

Na perspectiva de aprendizagem por RP, os alunos são considerados investigadores novatos e os professores são os orientadores da investigação. ${ }^{4,15}$ Nas atividades investigativas, a construção de conhecimento se dá através da resolução de problemas que envolve etapas como observações, elaboração de questões e hipóteses, consulta a fontes de informação, planejamento e execução de planos, coleta, análise e interpretação de dados, proposição de explicações, compartilhamento de informações. ${ }^{25-27}$

Essa metodologia requer dos alunos um comportamento ativo e um empenho para obter seus próprios resultados e está baseada na apresentação de situações abrangentes e sugestivas. Martinéz Aznar e Varela Nieto ${ }^{15}$ sugerem alguns passos para a implementação da RP:

1. Análise qualitativa do problema. Neste momento, indica-se a aproximação com a temática a ser estudada, a análise do enunciado do problema, a identificação das possíveis concepções alternativas acerca do assunto em questão e se necessário introduzir os subsídios teóricos pertinentes para a elaboração das hipóteses de resolução. A partir daí, deve-se reformular o problema de acordo com as interações dos alunos e, também, fazer as restrições necessárias. Destaca-se dessa etapa o estímulo à criatividade dos estudantes, pois partindo da proposta inicial, derivam-se diferentes questionamentos tangentes aos seus interesses.

2. Projeção de Hipóteses. Após a análise qualitativa, os estudantes possuem condições de especular hipóteses a fim de obter a solução para o problema de trabalho. Essas hipóteses vão auxiliar na interpretação dos resultados, pois a falta de dados para solucionar o problema irá desenvolver explicações provisórias a serem testadas.

3. Elaboração de estratégias de resolução. Essa etapa é composta pelas tentativas de modelação da resolução e é possível verificar e monitorar as variáveis com potencial para resolver o problema formulado. Pode-se criar um plano de trabalho com todos os materiais e procedimentos necessários, principalmente se a modelação envolver experimentos.

4. Resolução do problema. O professor deve conduzir essa etapa de modo mais flexível ao padrão e erro, deve auxiliar os estudantes a transpor obstáculos. O problema deve ser resolvido, preferencialmente, de maneiras diferentes por cada grupo, para que a análise dos dados permita que os estudantes comparem suas respostas e percebam suas coincidências. Além disso, o aluno deve ser estimulado a falar detalhadamente todos os processos e estratégias que foram utilizados, possibilitando o diagnóstico de possíveis falhas.

5. Análise de resultados. Essa análise deve ser profunda, para verificar a necessidade de uma revisão geral ou parcial das resoluções. É importante que todos os resultados sejam levados em consideração, a fim de verificar dificuldades pontuais dos estudantes, os principais conhecimentos desenvolvidos e as diferentes modelações utilizadas.

Acrescido do aporte teórico da Didática das Ciências, verifica-se que os princípios investigativos da RP convergem às orientações das atuais Diretrizes Curriculares Nacionais para a formação inicial em nível superior. ${ }^{28}$ No Art. $5^{\circ}$, há a indicação de que a formação de professores deve estar fundamentada na concepção de educação como processo emancipatório e permanente, respeitando a especificidade do trabalho docente, para que haja articulação entre teoria e prática e que o futuro profissional possa vivenciar dinâmicas pedagógicas que

contribuam para o exercício profissional e o desenvolvimento do profissional do magistério por meio de visão ampla do processo formativo, seus diferentes ritmos, tempos e espaços, em face das dimensões psicossociais, histórico-culturais, afetivas, relacionais e interativas que permeiam a ação pedagógica, possibilitando as condições para o exercício do pensamento crítico, a resolução de problemas, o trabalho coletivo e interdisciplinar, a criatividade, a inovação, a liderança e a autonomia (p. 6 , grifo nosso). ${ }^{28}$

Ademais, alguns estudos apresentam vantagens no uso da metodologia de RP na formação de professores, por possibilitar uma sólida formação científica e cultural, pois normalmente os problemas articulam os conhecimentos científicos com temas sociais. ${ }^{29-31}$

Dessa forma, instiga o futuro docente a desencadear várias habilidades que envolvem o seu processo de formação, ao pensar e criar situações investigativas. ${ }^{31}$ Esse exercício possibilita ao professor em formação relacionar o conhecimento de ciências a contextos, para favorecer o desenvolvimento da capacidade de abstração e raciocínio dos estudantes, contribuindo, assim, na construção do processo didático-pedagógico e também orienta o processo de estruturação de metodologias mais coerentes para as atuais necessidades educativas. ${ }^{30-32}$

Nesse sentido, propicia uma maior autonomia ao futuro docente para a elaboração dos planejamentos de aulas, tornando-se, dessa maneira, apropriada para a abordagem dos conteúdos científicos nos cursos de formação de professores.

Abreu e colaboradores ${ }^{30}$ inferem que a atividade de RP motiva os futuros docentes a ensinar Ciências Naturais, pois oportuniza o contato com situações de aprendizagem próximas à prática científica. Além disso, a discussão coletiva proporciona ao futuro docente rever seus conhecimentos prévios, suas crenças e concepções a respeito de como ensinar e aprender e, também, sobre os conhecimentos científicos. Possibilitando, assim, construir ações formativas ajustadas às suas necessidades de sala de aula. No entanto, os autores relatam que alguns sujeitos da pesquisa tiveram resistências para registrar o que tinham feito e aprendido durante as atividades, principalmente as elaborações escritas que deveriam ser feitas fora das horas de formação. ${ }^{30}$

$\mathrm{Na}$ investigação sobre o conceito de energia através da RP, na formação inicial de professores, ${ }^{15}$ é relatado que os licenciandos estão mais acostumados a obter a resolução para um problema proposto que verbalizar suas estratégias dessa resolução, principalmente quando se necessita de variáveis científicas. Essa tendência é justificada pela falta de familiarização com o exercício de explicar e explanar, indicando que é possivelmente uma questão inerente ao quadro teórico no qual os estudantes de licenciatura estão inseridos. Além disso, os licenciandos que trabalham com o modelo de resolução de problemas propostos evoluíram para visões mais complexas do conteúdo abordado. ${ }^{15}$

Goi e $\operatorname{Santos}^{31}$ apontam que ações formativas que possibilitam a autoria do professor na proposição de problemas e o aprofundamento teórico sobre as questões epistemológicas, pedagógicas e psicológicas 
da RP auxiliam no protagonismo do professor para o uso da metodologia nas aulas de Ciências.

Em vista disso, o objetivo principal desta experiência é identificar as formas de contribuição do uso da estratégia de RP para o desenvolvimento profissional de licenciandos em Química, no que tange aos aspectos teóricos e práticos da metodologia associada ao conteúdo de Ligações Iônicas.

\section{Ligações químicas}

O estudo das estruturas dos compostos depende basicamente da capacidade de relacionar suas propriedades químicas com as respectivas estruturas eletrônicas, por isso o entendimento sobre ligações químicas torna-se necessário. ${ }^{33}$ As ligações químicas entre átomos formam-se através do arranjo estrutural de seus elétrons no nível de valência. ${ }^{34}$ Num sólido iônico, por exemplo, a ligação pode ser descrita como o arranjo resultante de íons positivos e negativos mantidos pela atração eletrostática entre eles. Esse tipo de interação geralmente é chamada de ligação iônica. ${ }^{34}$ Os mesmos princípios utilizados no entendimento das moléculas também são usados no estudo desse tipo de sólidos. Portanto, compreender as alterações de energia presentes na formação dos íons e como eles interagem tornase interessante para o estudo das propriedades dos sólidos iônicos, como solubilidade, pontos de fusão e condutividade elétrica. ${ }^{35} \mathrm{Nesse}$ sentido, para estudar a ligação nos sólidos iônicos, utilizam-se teorias para facilitar a transição da química macroscópica para a química microscópica, como a Teoria Eletrostática ${ }^{36}$ e a Teoria de Bandas, ${ }^{37}$ principalmente em nível de formação superior.

No contexto da RP, optou-se por discutir sobre ligações químicas, mais especificamente sobre LI, visto o pequeno número de publicações sobre o tema relacionado às metodologias de ensino investigativas. Ademais, o conteúdo é de grande importância para a compreensão de outros conceitos químicos. Fernandez e Marcondes ${ }^{33}$ mostram que os alunos possuem grandes dificuldades conceituais sobre ligações químicas, como: a) confusão entre ligação iônica e covalente; b) antropomorfismos; c) regra do octeto; d) geometria das moléculas e polaridade; e) energia nas ligações químicas e f) representação das ligações.

Alguns autores argumentam que a dificuldade em aprender conceitos de ligações químicas está associada à sequência como as teorias são apresentadas, normalmente na ordem: ligação iônica, ligação covalente, polaridade e geometria. ${ }^{38,39}$ Além disso, estudos apontam que a estrutura curricular e os livros didáticos de diferentes países apresentam uma visão molecular da estrutura microscópica dos compostos iônicos. Esta configuração favorece que alunos descrevam que existem fórmulas moleculares para sais como o cloreto de sódio e o cloreto de potássio. ${ }^{1,2}$ Muitos equívocos como estes estão relacionados à sequência didática utilizada para ilustrar que na ligação iônica um único átomo de metal reage com um único átomo não metálico que forma uma unidade de fórmula, por exemplo, $\mathrm{NaCl}$ ou algum composto similar. Uma unidade de fórmula desenhada no quadro ou apresentada em um livro, sem uma explicação adequada, é idêntica para compostos moleculares tais como cloreto de hidrogênio. Neste contexto, os estudantes acabam não entendendo a ligação iônica como não direcional e as interações envolvidas na constituição dos retículos cristalinos dos sólidos iônicos e, por vezes, memorizam a compreensão de compostos iônicos como constituídos por moléculas. ${ }^{1,2}$

Além das simplificações e generalizações que são apresentadas para o estudo das teorias envolvidas, outro aspecto a ser considerado é o nível de abstração necessário para a compreensão destas teorias. ${ }^{2}$ Assim, os estudantes não conseguem interrelacionar os modelos utilizados para representar cada tipo de ligação com situações da vida real, como o estudo das propriades fisico-químicas dos materiais. , $38,39^{2}$
As afirmações feitas acima sobre as lacunas formativas dos alunos da educação básica são aplicáveis aos contextos de formação de professores nos cursos de licenciatura. ${ }^{1,38,39}$ Neste âmbito, considera-se que a vivência de uma ação formativa que aborde a contextualização dos princípios teóricos sobre ligações químicas, através da investigação sobre algumas propriedades fisico-químicas da matéria, como a experiência que é apresentada neste artigo, possa contribuir para a compreensão mais aprofundada dos conhecimentos químicos e dos pedagógicos referentes à metodologia de RP.

\section{A SEQUÊNCIA DIDÁTICA}

Neste trabalho, apresenta-se uma experiência de utilização da metodologia de RP na formação inicial de professores como forma de abordagem dos conceitos de LI. O estudo foi desenvolvido com cinco licenciados matriculados no Estágio de Docência em Ensino de Química I-C do curso de Licenciatura em Química Noturno da UFRGS, no segundo semestre de 2014.

Os dados foram coletados através de registros no Diário de $\mathrm{Campo}^{40}$ das professoras formadoras e com as produções escritas produzidas pelos licenciandos.

A sequência didática implementada foi adaptada de estudos anteriores ${ }^{15,25}$ e envolveu sete momentos distribuídos na seguinte ordem:

- Análise qualitativa do problema: I. Motivação; II. Elaboração dos grupos; III. Distribuição dos três problemas e materiais de consulta;

- Projeção de Hipóteses: IV. Discussão dentro dos grupos para elaboração das hipóteses de trabalho (como eles pretendem resolver os problemas);

- Elaboração de estratégias de resolução: V. Elaboração da apresentação das resoluções;

- Resolução do problema: VI. Plenária de apresentação das resoluções (cartazes, fotos, slides, teatro, vídeo);

- Análise de resultados: VII. Fechamento, no qual o professor realiza um levantamento sobre as principais modelações de resolução e ressalta os conceitos fundamentais discutidos.

Esses sete momentos foram desenvovidos em três semanas de quatro períodos cada, conforme se ilustra com a Tabela 1. Todas as atividades foram realizadas nas aulas presenciais realizadas no Laboratório de Informática.

A fim de propor uma abordagem sobre ligações em compostos iônicos, utilizaram-se como contextualização ${ }^{41}$ os sais presentes no Salar de Uyuni para a elaboração das situações-problema. O Salar de Uyuni é o maior deserto de sal do mundo e está situado ao sul da Bolívia, a mais de 3.000 metros acima do nível do mar. ${ }^{42}$ Esse salar possui uma crosta de sal de aproximadamente 10 metros de espessura e em seus interstícios se encontra uma salmoura. Os componentes majoritários da salmoura são: ións de sódio, magnésio, potássio, lítio, boro, cálcio, cloretos e sulfatos. A crosta de sal é formada principalmente por camadas de halita (cloreto de sódio - $\mathrm{NaCl}$ ) porosa (88-99\%), pequenas quantidades de gesso (sulfato de cálcio hidratado - $\mathrm{CaSO}_{4} 2 \mathrm{H}_{2} \mathrm{O}$ ) em grão fino e ulexita (borato de sódio e cálcio hidratado $\left.-\mathrm{NaCaBO}_{9} \cdot 8 \mathrm{H}_{2} \mathrm{O}\right) \cdot{ }^{43}$

O composto de maior interesse econômico do Salar de Uyuni é o lítio, que é extraido por um processo que forma carbonato de lítio. Também desse salar são obtidos outros produtos como o cloreto de sódio, de magnésio e o de lítio. ${ }^{42,43}$

Considera-se que, devido aos aspectos geográficos, históricos e dos processos fisico-químicos envolvidos na origem do salar, acrescido dos aspectos econômicos e ambientais associados aos processos de extração e utilização dos diferentes sais que o constituem, o Salar de Uyuni é um apropriado contexto ${ }^{41}$ para o estudo das ligações químicas, principalmente as LI. 
Tabela 1. Organização da sequência didática

\begin{tabular}{|c|c|c|}
\hline Semana & Momentos & Descrição \\
\hline 01 & I, II, III e IV & $\begin{array}{l}\text { Explanação feita pelas professoras formadoras sobre o Salar, a partir da apresentação de uma reportagem jornalística, no estilo } \\
\text { documentário, produzido para o programa de televisão Globo Repórter da emissora Rede Globo (http://g1.globo.com/globo- } \\
\text { reporter/noticia/2013/01/hotel-no-deserto-de-uyuni-na-bolivia-tem-paredes-e-moveis-feitos-de-sal.html). O documentário foi } \\
\text { utilizado para incitar a discussão com os estudantes sobre os conteúdos e contextos presentes nos problemas a serem resolvidos. } \\
\text { Organização das equipes de trabalho, seguida da leitura e análise dos problemas e materiais de consulta previamente seleciona- } \\
\text { dos pelas professoras formadoras, que incluíam artigos (http://qnesc.sbq.org.br/online/cadernos/05/hidrosfera.pdf; http://www. } \\
\text { quimica.net/emiliano/artigos/2005ago_qnc_sal.pdf; http://revistagalileu.globo.com/Revista/Galileu/0,,EDR87155-7943,00. } \\
\text { html; http://www.boliviacultural.com.br/ver_noticias.php?id=1013) e os Livros didáticos de Química apresentados no Guia } \\
\text { do PNLD 2015. O úlitmo momento foi direcionado para a elaboração das hipóteses de trabalho. }\end{array}$ \\
\hline 02 & $\mathrm{~V}$ & $\begin{array}{l}\text { Discussão dentro dos grupos para elaboração das apresentações em slides e aprofundamento da investigação através do acesso } \\
\text { à biblioteca eletrônica Scielo (com o uso das palavras-chave "ligações químicas" e "Salar de Uyuni"). }\end{array}$ \\
\hline 03 & VI e VII & $\begin{array}{l}\text { Plenária de apresentação das resoluções em slides. } \\
\text { Debate coletivo, durante o qual as professoras formadoras realizaram um levantamento sobre as principais modelações de } \\
\text { resolução e ressaltaram os conceitos fundamentais discutidos. }\end{array}$ \\
\hline
\end{tabular}

De acordo com Pozo e Crespo, ${ }^{44}$ os problemas propostos nesta experiência didática são classificados como escolares, os quais têm por objetivo desenvolver conceitos, procedimentos e atitudes cabíveis à ciência que possibilitam a compreensão dos acontecimentos cotidianos; semiabertos, pois os enunciados apresentam parcialmente os subsídios necessários para a sua resolução; qualitativo, uma vez que os estudantes podem utilizar conceitos científicos e teorias, sem a necessidade de cálculos ou raciocínio matemático; e teórico-prático, porque aceita estratégias experimentais e raciocínios teóricos para resolvê-los. Destaca-se que os problemas semiabertos qualitativos possibilitam que os próprios estudantes incorporem ideias e estratégias com as quais seja possível definir e resolver a tarefa.

Os três problemas elaborados foram validados por pesquisadores da área de Ensino de Química, quanto à adequação conceitual, contextual e estrutural dos problemas.

O Problema 1 " $O$ deserto de Uyuni é o maior Salar do mundo, contendo mais de 64 bilhões de toneladas de cloreto de sódio, 150 milhões de toneladas de cloreto de potássio, 100 milhões de cloreto de magnésio e ainda guarda uma imensa reserva de Lítio com cerca de 100 milhões de toneladas. Atualmente a região do Salar vivencia a exploração de lítio, visto que esse metal atualmente é utilizado para diferentes finalidades. Pesquise qual o processo utilizado para a extração de Lítio no deserto de Uyuni. Cite duas aplicações do Lítio na atualidade e explique se essas aplicações causam impactos ambientais positivos ou negativos" visa ao estudo teórico sobre as aplicações do Lítio e questões ambientais, dessa forma, está relacionado a um dos contextos apresentados no Vídeo utilizado para a motivação inicial sobre o processo de extração do metal. Os Problemas 2 e 3 possuem por finalidade um aprofundamento no conteúdo de ligações iônicas.

O Problema 2 “A Oceanografia Química é a ciência que estuda a composição e a concentração dos compostos presentes nos oceanos. A composição da água do mar é basicamente constante e possui mais de 70 elementos dissolvidos. Embora a água do mar seja constituída de 3,5\% de sais dissolvidos, somente dois terços são cloreto de sódio. Como o Salar de Uyuni foi originado da evaporação de águas do Oceano Pacífico, pesquise quais são os principais íons que compõem a água do mar. Represente com modelos físicos (palitos, bolas, desenhos, representações teatrais) como seria a imagem submicroscópica dos íons quando estão solvatados na água. Explique duas propriedades da água do mar que estão relacionadas à presença destes íons" apresenta alguns dados sobre a composição da água do mar e, através dessa informação, solicita aprofundamento quanto à representação submicroscópica da solvatação dos íons em água e favorecendo a discussão sobre a composição dos retículos cristalinos e das propriedades dos compostos iônicos.
Esse problema está relacionado ao histórico apresentado aos licenciandos sobre o Salar, visto que esse, provavelmente, tenha se originado durante o processo de formação das Cordilheiras dos Andes, aprisionando parte das águas do Oceano Pacífico e formando lagos salgados que, com o passar do tempo, evaporaram formando o Salar. ${ }^{42,43}$

No caso do Problema 3, "Os períodos de chuvas, entre dezembro e março, contribuem para a expansão das margens do Salar de Uyuni. Sabe-se que isso acontece por conta do processo constante de evaporação da água. Explique, utilizando teorias de ligações químicas, a grande diferença de Ponto de Fusão da água e dos sais que constituem o Salar. Simule experimentos práticos para ilustrar essa diferença" optou-se por utilizar um evento natural do Salar para abordar sobre o processo de evaporação da água e, assim, questionar sobre o ponto de fusão dos sais presentes, complementando a discussão iniciada no Problema 2 sobre as propriedades dos compostos iônicos. Nesse problema, foi solicitado que os futuros professores utilizassem atividades experimentais, a fim de explicar as diferenças encontradas.

$\mathrm{O}$ intuito da atividade formativa foi instrumentalizar os docentes para o uso da metodologia em suas futuras salas de aula. Entendese que a vivência da metodologia investigativa no papel de aluno pode favorecer a compreensão dos futuros professores sobre a importância do uso de perspectivas didáticas contemporâneas nas aulas de Química. De acordo com Santos e Goi, ${ }^{31}$ muitos professores têm carências conceituais e metodológicas para trabalhar em sala de aula a metodologia de RP e é visível o quanto esses educadores utilizam basicamente estratégias do ensino tradicional devido à falta de preparo.

\section{RESULTADOS E DISCUSSÃO}

\section{Aspectos conceituais, procedimentais e atitudinais}

No momento I, de aproximação dos licenciandos ao conteúdo de ligações químicas, foi realizada uma abordagem em nível de revisão de conteúdos, sobre a ligação dos sólidos iônicos e suas propriedades (solubilidade, pontos de fusão, ponto de ebulição, condutibilidade). Para motivar a discussão, foi apresentado um vídeo sobre o Salar de Uyuni. Durante a apresentação do vídeo sobre o Salar, os licenciandos demonstraram muito interesse sobre o local e solicitaram informações sobre seu histórico e principalmente sobre o Hotel de Sal que é apresentado no documentário, onde móveis e estrutura física são de blocos de sal. Conforme registros no Diário de Campo, um dos licenciandos questionou: 
"Professora, mas como que os blocos não se desmancham com a água no período das chuvas, ou quando um hóspede deixa cair um copo de água sobre um móvel? ”

Esse questionamento foi enriquecedor, pois possibilitou que a professora formadora introduzisse a discussão sobre a relação do tipo de ligação química e solubilidade das substâncias em água. Com respeito à ligação química, foi possível aprofundar os conceitos de ligações em sólidos iônicos, especificamente pelo modelo eletrostático e pela definição de energia reticular.

O modelo eletrostático define que os sólidos iônicos são formados por interações eletrostáticas de íons de cargas opostas. A energia reticular representa a energia liberada quando um mol de pares de íons no estado gasoso se aproxima até atingir uma distância de equilíbrio a fim de gerar um sólido iônico. ${ }^{35} \mathrm{~A}$ energia reticular pode ser explicada com a equação de Born-Landé (Equação 1), na qual são consideradas as forças de atração e as forças de repulsão entre os íons de carga oposta. ${ }^{36} \mathrm{~A}$ energia reticular é fortemente influenciada pela carga dos íons e a distância entre os íons.

$$
U_{0}=A \frac{N q^{+} q^{-} e^{2}}{4 \pi \varepsilon r}\left(1-\frac{1}{n}\right)
$$

Na Equação 1, Uo é a energia reticular, $e=1,6 \times 10^{-19} \mathrm{C}$ (carga do elétron), $A$ é a constante de Madelung (os valores dependem do tipo de sólido iônico), $\varepsilon$ é a permissividade de carga no vácuo $\left(8,5 \times 10^{-12} \mathrm{C}^{2} \mathrm{~J}^{-1} \mathrm{~m}^{-1}\right), q+\mathrm{e} q$ são as cargas dos íons, $n$ é o expoente de Born (o valor depende da configuração eletrônica dos íons) e $r$ é a distancia entre os íons.

Também foi possível explicar o mecanismo de dissolução dos sólidos iônicos. A solubilidade dos sólidos iônicos em água está relacionada diretamente com a energia reticular e pode ser influenciada pela diferença do tamanho do raio dos íons. ${ }^{35}$ Geralmente, quando o sólido iônico está formado por cátions e ânions de raios semelhantes, possuem fraca atração com as moléculas de água, portanto possuem pouca solubilidade. Entretanto, se os íons são de raios diferentes, geralmente são mais solúveis em água. ${ }^{36}$

Compreende-se que, para o estudante, os blocos eram conformados somente do sal cloreto de sódio $(\mathrm{NaCl})$ que é solúvel em água. Entretanto a composição dos blocos, extraídos do Salar, compreende também outros minerais, em menor quantidade, como por exemplo o gesso $\left(\mathrm{CaSO}_{4} \cdot 2 \mathrm{H}_{2} \mathrm{O}\right)$, que é pouco solúvel em água. ${ }^{43}$ Esse sólido iônico é conformado por íons de tamanhos semelhantes e a pouca solubilidade pode ser devida à considerável energia reticular que não pode ser compensada pela entalpia de solvatação. ${ }^{35,37}$

O mecanismo de formação de soluções depende das intensidades relativas de forças atrativas entre as partículas do soluto (energia reticular) e forças atrativas entre as partículas do solvente (entalpia de intrusão), além das forças que surgem entre as partículas do soluto e do solvente (entalpia de solvatação), durante o processo de dissolução. ${ }^{35}$ No caso da dissolução de compostos iônicos, a solução é formada quando a atração eletrostática entre os íons no retículo (energia reticular) é superada pela entalpia de solvatação. ${ }^{37}$ Portanto, a capacidade de dissolução de um sal é fortemente influenciada pela energia envolvida na dissolução do soluto (entalpia de dissolução), conforme Equação 2. ${ }^{37}$

$\Delta \mathrm{H}_{\text {dissolução }}=\Delta \mathrm{H}_{\text {solvatação(ion-água) }}+\Delta \mathrm{H}_{\text {reticular(ion-íon) }}+\Delta \mathrm{H}_{\text {intrusão(água-água) }}$

Apesar da intensidade da interação íon-íon ser maior do que a da interação dipolo-dipolo do solvente, e do que a da interação soluto-solvente (íon-dipolo), o elevado número de interações íon-dipolo, que atua em cada íon, pode compensar a força de atração eletrostática que mantém os íons unidos no retículo. ${ }^{37}$
Dessa forma, o momento I, além de motivar a atividade investigativa, também favoreceu a introdução de conceitos importantes para a elaboração das hipóteses de resolução para os problemas.

Entende-se que esse momento de discussão pode ter contribuído para esclarecer as dificuldades conceituais dos licenciandos sobre a relação ligação química/solubilidade, além de servir como um exemplar de abordagem para os conteúdos de ligações químicas no ensino médio. Isso se deve ao fato de os professores em formação relatarem dificuldades acerca de formas de adequação do conteúdo abordado e de metodologias apropriadas para explicar Ligações Químicas, pois os conteúdos adquiridos na formação acadêmica foram apresentados de forma expositiva e sem vínculo com algum tema ou contexto.

Após a discussão sobre o vídeo, no momento II, os licenciandos foram divididos em um trio chamado de grupo A e em uma dupla chamada de grupo B.

No momento III, foram apresentados e lidos os três problemas desenvolvidos para a atividade formativa com o intuito de verificar possíveis obstáculos iniciais por parte dos futuros professores e, também, mostrar as sugestões de referências, a fim de facilitar o desenvolvimento da atividade. Nesse terceiro momento os sujeitos foram informados de que deveriam elaborar hipóteses de resolução para os problemas em sequência. Os grupos não apresentaram dificuldades quanto à compreensão dos enunciados dos problemas e buscaram algumas informações nos materiais indicados pelas professoras formadoras e em outras fontes na Internet para elaboração das hipóteses, conforme indicado na Tabela 1.

Durante o momento IV do processo formativo, surgiram discussões entre os licenciandos e a professora formadora, a qual em todos os momentos questionava-os sobre suas hipóteses e afirmações. De acordo com Carvalho e Gil-Pérez, ${ }^{5}$ os professores assumem o papel de orientadores e mediadores nas atividades de investigação dirigida. Nesse sentido, devem argumentar sobre o problema em questão, para que os estudantes possam compreendê-lo, auxiliar no acesso a outras fontes de conhecimento e discutir os dados obtidos interligando-os com as hipóteses levantadas, para verificar se a tarefa está efetivamente sendo realizada pelas modelações de resolução propostas.

No decorrer do quarto momento, o Grupo A fez alguns questionamentos como "Será que o aluno não irá sentir-se frustrado por não achar a resposta logo de cara"? Entende-se que essa pergunta do licenciando refletiu a sua própria sensação de frustração, visto que o grupo apresentou dificuldades em descrever e relacionar os conhecimentos teóricos sobre LI e as propriedades dos sais. O Grupo B também se mostrou com dificuldades em relacionar conceitos químicos: "os alunos conseguiriam fazer a conexão entre ligações químicas e ponto de fusão"? Compreende-se que essa indagação está diretamente relacionada à dificuldade enfrentada pelo Grupo B em esclarecer a relação entre ponto de fusão e ponto de ebulição, com o tipo de ligação dos materiais. Dúvida que surgiu durante o trabalho de elaboração das hipóteses de trabalho.

Goi e Santos ${ }^{31}$ apontam que lacunas conceituais são normalmente identificadas no momento de elaboração ou de resolução dos problemas.

Frente a esse questionamento, a professora formadora introduziu a relação da energia reticular dos sólidos iônicos com os valores de pontos de fusão e ebulição. Destacou que quanto maior a energia reticular, maior são os valores de ponto de fusão. ${ }^{36}$

Comparado aos sólidos iônicos, a água apresenta um menor ponto de fusão e ebulição. A água é uma molécula formada por ligações covalentes entre o oxigênio e o hidrogênio, de geometria angular e de momento de dipolo 1,85 debye, logo, é polar. ${ }^{34}$ No estado condensado da água, são as ligações de hidrogênio que interatuam e que são muito mais fracas que a ligação iônica, fazendo com que ela apresente ponto de fusão e ebulição mais baixos que os sólidos iônicos..$^{34,35}$ 
As dificuldades conceituais identificadas durante a discussão, possivelmente, são oriundas do processo de memorização que esses sujeitos recorrem durante a sua formação acadêmica. Conforme estudos realizados sobre o Curso de Licenciatura em Química da UFRGS, a maioria das disciplinas de conhecimentos específicos possui um perfil mais conceitual, nas quais o método de transmissão dos conhecimentos teóricos e acadêmicos é o mais utilizado. ${ }^{45}$

Outra questão apontada pelo Grupo B foi sobre o tempo disponibilizado para a resolução dos problemas em sala de aula, "Mas afinal, daremos conta de vencer o conteúdo, disponibilizando tempo em sala de aula para a elaboração das pesquisas"? As professoras formadoras esclareceram que a atividade de RP favorece a elaboração de argumentos sobre os conteúdos estruturantes selecionados e contextos trabalhados, auxiliando na apropriação dos conhecimentos científicos, conforme verificado em estudos anteriores. ${ }^{5,13,27,29}$

Durante o momento V, o Grupo B interagiu bastante entre si e engajou-se na utilização da bibliografia indicada pelas professoras formadoras e na busca de outras fontes de informações, assim como na organização das explicações e nas ilustrações que utilizaram para preparar sua apresentação com as resoluções. O Grupo A apresentou-se menos interativo e mais disperso, buscaram recursos na internet como repositórios digitais de práticas de laboratório. Conforme os registros no Diário de Campo, esse grupo foi pouco organizado na elaboração da apresentação das resoluções. Eles utilizaram os Livros didáticos após argumentação e sugestão da professora formadora, demonstrando menor autonomia que o Grupo B.

Segundo Vasconcellos, ${ }^{46}$ os conteúdos são um conjunto de conhecimentos, hábitos e atitudes, organizados pedagógica e didaticamente. Eles são o meio para a concretização das finalidades que o educador tem ao preparar o seu curso a partir da realidade. Ainda segundo o autor, existem três tipos de conteúdos: conceitual, procedimental e o atitudinal. Os conteúdos conceituais envolvem o conhecimento de fatos, fenômenos, princípios e leis, enquanto que os conteúdos procedimentais abrangem o saber fazer, o domínio das habilidades. Por fim, os atitudinais compreendem o saber ser, o envolvimento, o interesse, a postura e as vontades dos alunos.

Nesse sentido, entende-se que a sequência didática desenvolvida contribuiu para o desenvolvimento de aprendizagens conceituais como a relação entre as teorias de ligações iônicas e algumas propriedades dos materiais; procedimentais como a argumentação em público, a leitura e manipulação de diferentes fontes de referências bibliográficas; e atitudinais como a interação entre os discentes e docentes durante as diferentes etapas da ação formativa, a autonomia na proposição de hipóteses para a resolução dos problemas e a capacidade de trabalhar em grupo. Ademais, os problemas elaborados possibilitaram a vivência de atividades que associaram o estudo de teorias, representações submicroscópicas e fenômenos macroscópicos.

\section{As resoluções dos problemas}

O momento VI foi direcionado à apresentação de todas as informações utilizadas para a resolução dos problemas, assim como a modelação utilizada para resolvê-los.

Na resolução do problema 2, as hipóteses do Grupo B foram "Água do mar contém $\mathrm{NaCl}$ e outros sais que conhecemos", "A água do mar conduz eletricidade" e "Na água os íons estão soltos". Na plenária, o grupo apresentou uma tabela composta por íons presentes na água doce e na água salgada, para destacar que alguns íons estão presentes nos dois meios. Também utilizaram a representação da estrutura cristalina do cloreto de sódio, e deste sal em sua forma solvatada em água, para explicar a condutividade em água.

As ilustrações utilizadas pelo grupo representaram de forma apropriada os íons estabilizados na forma solvatada, pois estes estavam coordenados pelas moléculas de água por interação intermolecular do tipo íon-dipolo. Os cátions $\mathrm{Na}^{+}$estavam interagindo com o dipolo negativo (oxigênio das moléculas de água) e os ânions $\mathrm{Cl}^{-}$estavam interagindo com o dipolo positivo (os hidrogênios das moléculas de água). As imagens utilizadas pelo grupo foram extraídas de um dos artigos indicados pelas professoras formadoras como fonte de consulta (http://www.quimica.net/emiliano/artigos/2005ago_qnc_sal.pdf).

No momento das apresentações, as professoras formadoras enfatizaram a relevância de esclarecer para os alunos que as fórmulas químicas utilizadas para representar os sólidos iônicos ( $\mathrm{NaCl}$ para o cloreto de sódio) expressam somente a razão entre os íons em uma cela unitária ${ }^{36}$ e não o número de coordenação dos íons (número de contra-íons em torno dos íons) no retículo do sólido. ${ }^{1,34}$ Os modelos representativos dos retículos cristalinos e dos íons solvatados apresentados pelo Grupo B foram utilizados para ilustrar essa etapa da discussão.

O Grupo A apresentou as hipóteses de que "Há mais tipos de sais na água do mar em relação à água do lago" e de que "A água do mar pode conduzir corrente elétrica assim como a água com $\mathrm{NaCl}$ ”? $\mathrm{Na}$ plenária, o grupo demonstrou as diferenças de propriedades entre os dois tipos de água com um vídeo sobre um experimento de condutividade entre soluções de ácido, de base, de sal e de açúcar. Os licenciandos apenas explicaram o mecanismo de dissolução dos sais em água, mas não utilizaram e nem ilustraram representações da interação entre íons e água. O vídeo utilizado foi localizado pelo grupo nos momentos de acesso à internet (http://www.pontociencia. org.br/experimentos/visualizar/testador-de-condutividade/203).

Conforme relatos na literatura, os professores podem favorcer a maior compreensão dos conteúdos relacionados às ligações químicas ao enfatizarem a relação entre o nível macroscópico e submicroscópico, seja com modelos físicos, modelos matemáticos, diagramas de energia, representações simbólicas e fenômenos observacionais como as propriedades fisico-químicas dos materiais. ${ }^{1,2,47}$ Alguns autores destacam a importância dos estudantes se apropriarem dos aspectos fundamentais das ligações, como as interações eletrostáticas, no caso da ligação iônica, para poderem complexificar tais conhecimentos quanto à força das ligações, às estruturas e propriedades dos distintos materiais analisados. . $^{1,247}$

O Grupo B, na resolução do Problema 3, tomou por hipóteses que "O ponto de ebulição dos sais deve ser muito mais elevado que da água, porque virou um deserto de sal devido à evaporação da água" e que "Um experimento pode ser feito com água normal e água com bastante sal e ver o que ocorre". Na plenária, apresentaram os pontos de fusão dos sais que compõem o Salar e da água, assim como vídeos com experimentos que mostram as diferenças entre os pontos de fusão das substâncias em questão; também trouxeram uma tabela com as principais fontes de lítio, suas propriedades, como ocorre a solvatação e como isso afeta as propriedades químicas e imagens do Salar de Uyuni. Além disso, explicaram uma tabela comparativa entre a composição do Salar e a composição da água do mar; buscaram na internet os pontos de fusão e ebulição dos principais sais presentes no deserto de sal; e teorizaram através dos livros didáticos e de ilustrações as diferenças entre as ligações químicas presentes nos sais (ligações iônicas) e na água (ligação covalente e ligação de hidrogênio).

Já o Grupo A não propôs hipóteses para o Problema 3. Os licenciandos preferiram pesquisar as definições dos tipos de ligações (iônica e covalente) na internet, para explicar de forma genérica a diferença entre o ponto de fusão do cloreto de sódio e da água. O grupo utilizou um vídeo que mostrava um experimento caseiro de evaporação da água do mar (https://www.youtube.com/watch?v=osmsWTIpNss). Entende-se que esse grupo, por não ter pesquisado quais os sais que compõem o Salar, generalizou suas conclusões para o cloreto de sódio, visto que a prática demonstrada resultava nesse sal sólido após a evaporação da água. 
A professora formadora finalizou essa etapa explicando que outra propriedade dos sólidos iônicos é a desprezível condutividade elétrica, pois geralmente apresentam um gap muito alto. Existe um impedimento do movimento dos elétrons quando a diferença de energia entre a banda de valência e a banda de condução, o gap, for maior que $3.0 \mathrm{eV}^{36}$ e também a banda de valência for preenchida, gerando um material isolante. ${ }^{37}$ Por exemplo, o $\mathrm{NaCl}$ apresenta um gap de $7.0 \mathrm{eV}$, entretanto, quando dissolvido em solventes aquosos a condutividade é dada por condução iônica. ${ }^{37}$

Conforme registros no Diário de Campo, nos momentos iniciais da ação formativa os estudantes apenas expressaram dificuldades sobre como adequar os conteúdos de ligações químicas para o nível da Educação Básica, porém, durante a atividade de resolução dos problemas apresentaram algumas dificuldades ao terem que aplicar tais conhecimentos aos fenômenos e contextos que foram discutidos em aula.

Os dados revelaram pequena diversificação das estratégias teóricas para a resolução dos problemas, pois os licenciandos optaram por utilizar majoritariamente as fontes de pesquisa indicadas pelas professoras formadoras. Entretanto, os grupos inovaram com a utilização de vídeos que apresentavam práticas experimentais ao invés de proporem experimentos com vidrarias e reagentes. Entende-se que a realização das atividades no Laboratório de Informática favoreceu essa escolha. A utilização dos vídeos com diferentes testes de condutibilidade elétrica enriqueceu a discussão sobre o mecanismo de dissolução dos sólidos iônicos e das propriedades físico-químicas da água do mar.

\section{Contribuições da ação formativa}

No momento VII, as professoras formadoras conduziram o debate sobre as principais modelações de resoluções utilizadas, as dificuldades enfrentadas e os conceitos fundamentais abordados. Para tanto, discutiu-se sobre alguns aspectos das apresentações dos dois grupos, mostrando algumas lacunas conceituais identificadas, como a expressão "soltos" utilizada pelo Grupo B, assim como a falta da explicação do experimento de condutividade das soluções de sal, de base, de ácido e de açúcar utilizado pelo Grupo A. Esse comportamento foi relatado na investigação realizada por Martinéz Aznar e Varela Nieto. ${ }^{15}$ Os referidos autores verificaram que os licenciandos estão mais acostumados a obter a resolução para um problema proposto do que verbalizar suas estratégias dessa resolução, principalmente quando se necessita de termos científicos.

Ademais, destaca-se que os grupos não utilizaram modelos físicos para representar a imagem submicroscópica dos íons solvatados na água, entretanto, os grupos demonstraram certo domínio conceitual para explicar as interações entre soluto (sais) e solvente (água) no mecanismo de dissolução. Outro apontamento da professora formadora foi que os dois grupos utilizaram a condutividade elétrica como propriedade da água do mar para resolver o Problema 2.

No momento final da plenária, a participação dos estudantes foi efetiva na discussão sobre as possibilidades de resoluções sobre os problemas. Dessa forma, foi possível verificar que os licenciandos se apropriaram dos conhecimentos conceituais trabalhados, como a teoria eletrostática e o mecanismo de dissolução e, enfim, conseguiram relacioná-los às propriedades dos materiais.

Os licenciandos foram questionados se durante a atividade de RP surgiu alguma dúvida sobre os conteúdos de LQ. As colocações em aula, majoritariamente, apontaram que os licenciandos apresentam-se inseguros, principalmente sobre o nível de profundidade da abordagem para a Educação Básica, conforme ilustra-se com os registros do Diário de Campo:

\author{
"Mesmo estando no final do curso, não tenho domínio \\ pleno"; \\ "Sempre surgem dúvidas e dificuldades para lembrar estes \\ conteúdos"; \\ "Não sei traduzir os conceitos e teorias estudados na gra- \\ duação para linguagem dos alunos".
}

Quando questionados sobre as dificuldades e contribuições da experiência de resolver problemas, os licenciandos descreveram que a vivência da metodologia investigativa favoreceu a compreensão sobre a importância de abordagens que possibilitam a relação entre as propriedades dos materiais para o estudo dos conteúdos de LQ, pois conseguiram mitigar dúvidas conceituais sobre teorias e modelos representacionais já estudados em disciplinas anteriores. Esse grupo de sujeitos também apontou que vivenciar atividades para serem realizadas em grupo é um diferencial, visto que na maior parte das disciplinas de conhecimentos específicos do curso as ações formativas são individuais. Destaca-se que o trabalho em grupo favoreceu a interação entre os sujeitos. Além disso, os estudantes afirmaram que a atividade contribuiu para esclarecer como a perspectiva investigativa de ensino e a contextualização podem motivar e instigar os alunos no estudo dos conhecimentos químicos, pois foi assim que eles se sentiram.

Essas colocações apontam a relevância de ações formativas sobre os conteúdos que são fundamentais para a futura prática profissional docente, associados à experimentação de metodologias ativas de ensino com eles no papel de alunos. Sendo assim, destaca-se que essa proposta didática de perspectiva investigativa relaciona as propriedades dos materiais, como solubilidade, condutividade, pontos de fusão e ebulição com o tipo de ligação química das substâncias, e atende às contemporâneas orientações sobre o ensino de Química. ${ }^{7,29,38}$

Ademais, considera-se que o desenvolvimento de atividades que associam conhecimentos conceituais da Química aos didáticos das Ciências, como a metodologia de RP, podem favorecer a formação de professores mais autônomos e seguros para utilizar diferentes recursos metodológicos em suas futuras ações profissionais na Educação Básica.

\section{CONCLUSÕES}

A análise da experiência formativa desenvolvida evidenciou que a vivência da metodologia de RP no papel de alunos favoreceu a identificação de possibilidades de perspectivas de ensino, para os conteúdos de Ligações Iônicas/Químicas, para as futuras atuações profissionais dos licenciandos que participaram desta investigação. Salienta-se que experienciar a metodologia de ensino estudada contribui para a apropriação dos recursos didáticos necessários para a condução das rotinas de sala de aula frente a uma abordagem investigativa de aprendizagem. Conforme as $\mathrm{DCN}^{28}$ e pesquisadores da área de formação de professores, ${ }^{6-8,15}$ a situação de formação profissional do professor é inversamente simétrica à situação de seu exercício profissional, logo, ele deve viver como aluno as organizações e orientações pedagógicas que lhes serão exigidas em futura atuação profissional.

Além disso, evidenciaram-se contribuições da sequência didática implementada para o desenvolvimento de conteúdos conceituais, procedimentais e atitudinais. ${ }^{46}$

Como conhecimentos procedimentais infere-se que a ação formativa possibilitou um espaço para a leitura de diferentes fontes de referências bibliográficas, para a argumentação em público e para inter-relacionar conhecimentos específicos da Química com os pedagógicos. Como atitudinais verificou-se a expressiva interação entre os discentes e docentes durante as diferentes etapas da ação 
formativa, a autonomia na proposição de hipóteses para a resolução dos problemas e a capacidade de trabalhar em grupo.

Quanto aos aspectos conceituais destaca-se a relação entre as teorias de ligações iônicas e algumas propriedades dos materiais, como a solubilidade dos sólidos iônicos em água, que é influenciada pela diferença no tamanho do raio dos íons e está relacionada diretamente com a energia reticular, ${ }^{35}$ assim como os elevados pontos de fusão e ebulição. ${ }^{36}$ Considera-se que a escolha do tema Salar de Uyuni, para a aproximação dos estudantes com o conteúdo, motivou os grupos e mostrou-se rico para a contextualização dos conhecimentos científicos com os ambientais, sociais e tecnológicos apresentados nos problemas que foram propostos. Ademais, os problemas elaborados possibilitaram a vivência de atividades que associaram o estudo de teorias, representações submicroscópicas e fenômenos macroscópicos.

Entretanto, percebeu-se que os estudantes que participaram da sequência didática, mesmo cursando etapas finais do curso de licenciatura, possuiam dificuldades conceituais sobre ligações químicas, sobre como adequar os conhecimentos acadêmicos para a Educação Básica, sobre como resolver problemas, trabalhar em grupo e tomar decisões. Dessa forma, a metodologia de ensino apresentada nesse estudo mostrou-se eficaz para o aperfeiçoamento desses conhecimentos e, portanto, para a formação profissional desses estudantes.

\section{REFERÊNCIAS}

1. Vladusic, R.; Bucatb, R. B.; Ozic, M.; Chem. Educ. Res. Pract. 2016, 17,685 .

2. Nimmermark, A.; Öhrström, L.; Martenssona J.; Davidowitz, B.; Chem. Educ. Res. Pract. 2016, 17, 985.

3. Vieira, H.; Morais, C.; Paiva, J.; Quim. Nova 2014, 37, 1573.

4. Cortés, A. L. G.; de la Gándara, M. G.; Enseñanza de las Ciencias 2006, $25,435$.

5. Carvalho, A. M. P.; Gil-Pérez, D.; Formação de Professores de Ciências: tendências e inovações, Cortez: São Paulo, 2006.

6. Maldaner, O. A.; A Formação Inicial e Continuada de Professores de Química: Professores/Pesquisadores. Unijuí: Ijuí, 2000.

7. Schnetlzer, R. Apontamentos sobre a história do ensino de química no Brasil; Santos, W. L. P., Maldaner, O. A., orgs.; Unijuí: Ijuí, 2010, cap. 2 .

8. Pinheiro, A. N.; Medeiros, E. L.; Oliveira, A. C.; Quim. Nova 2010, 33, 1996.

9. Herreid, C. F.; J. Chem. Educ. 2013, 90, 256

10. Gil-Pérez, D.; Ensen. Cienc. 1994, 12, 154.

11. Silva, S. F.; Núñez, I. B.; Quim. Nova 2002, 25, 1197

12. Gil-Pérez, D.; Furió, C. M.; Valdés, P.; Salinas, J.; Torregrosa, J. M.; Guisasola, J.; González, E.; Dumascarré, A.; Goffard, M.; Carvalho, A. M. P.; Enseñanza de las Ciencias 1999, 17, 311.

13. Yuriev, E.; Naidu, S.; Schembri, L. S.; Short, J. L.; Chem. Educ. Res. Pract. 2017, 18, 486.

14. Passos, C. G.; Santos, F. M. T.; Anais do XV Encontro Nacional de Ensino de Química, Brasília, Brasil, 2010.

15. Martinéz Aznar, M. M.; Varela Nieto, M. P.; Enseñanza de las Ciencias 2009, 27, 343 .
16. Bodner, G. M.; Bhattacharyya, G.; Educ. Quim. 2005, 16, 222.

17. Sá, L. P.; Queiroz, S. L.; Estudo de Casos no ensino de Química, Editora Átomo: Campinas, SP, 2010.

18. Herreid, C. F.; J. Chem. Educ. 1994, 23, 221.

19. Ozdilek, Z.; Chem. Educ. Res. Pract. 2015, 16, 39

20. Massena, E. P.; Guzzi Filho, N. J. de, Sá, L. P.; Quím. Nova 2013, 36, 1066.

21. Velloso, A. M. S.; Motheo, A. J.; Queiroz, S. L.; Revista Electrónica de Enseñanza de las Ciencias 2009, 8, 593.

22. Overton, T. L.; Bradley, J. S.; Chem. Educ. Res. Pract. 2010, 11, 124.

23. Martínez, F. P.; Martínez Aznar, M. M.; Enseñanza de las Ciencias 2014, 32, 469.

24. Gulacar, O.; Overton, T., Bowman, C. R.; Fynewever, H.; Chem. Educ. Res. Pract. 2013, 14, 507.

25. Goi, M. E. J.; Santos, F. M. T.; Quim. Nova Esc. 2009, 31, 203.

26. Shahat, M. A.; Ohle, A.; Treagust, D.; Fischer, H. E.; Int. J. Sci. Math. Educ. 2013, 11, 1157.

27. Hofstein, A.; Lunetta, V. N.; Sci. Educ. 2004, 88, 28.

28. Brasil. Ministério da Educação. Conselho Nacional de Educação. Diretrizes Curriculares Nacionais para a Formação Inicial em Nível Superior (cursos de licenciatura, cursos de formação pedagógica para graduados e cursos de segunda licenciatura) e para a formação continuada. Resolução CNE/CP 02, 2015.

29. Vilches, A.; Gil-Pérez, D.; Tecné, Episteme y Didaxis 2007, 22, 67.

30. Abreu, L.; Bejarano, N.; Hohenfeld, D.; Investigações em Ensino de Ciências 2013, 18, 23.

31. Goi, M. E. J.; Santos, F. M. T.; Investigações em Ensino de Ciências 2014, 19, 431.

32. Sevian, H.; Bernholt, S.; Szteinberg, G. A.; Augustea, S.; Pérez, L. C.; Chem. Educ. Res. Pract. 2015, 16, 429.

33. Fernandez, C.; Marcondes, M. E. R.; Quim. Nova Esc. 2006, 24, 20.

34. Atkins, P. W.; Princípios de química: questionando a vida moderna e o meio ambiente, 5. ed., Bookman: Porto Alegre, 2012.

35. Shriver, D. F.; Atkins, P. W.; Inorganic chemistry, $4^{\text {th }}$ ed., Bookman: Porto Alegre, 2008.

36. Benvenutti, E. V.; Química inorgânica: átomos, moléculas, líquidos e sólidos, $3^{\mathrm{a}}$ ed., Editora da UFRGS: Porto Alegre, 2011.

37. Huheey, J. E.; Química Inorgánica: Principios de estructura y reactividad, 4ª ed., Oxford University Press: México, 1997.

38. Dhindsa, H. S.; Treagust, D. F.; Chem. Educ. Res. Pract. 2014, 15, 435.

39. Nahum, T. L., Mamlok-Naaman, R.; Hofstein, A.; J. Chem. Educ. 2008, $85,1680$.

40. Porlán, R.; Martín, J.; El diario del profesor: Un recurso para la investigación en el aula, $6^{\mathrm{a}}$ ed., Díada: Sevilla, 1998.

41. Santos; W. L. P.; Ciência \& Ensino 2007, 1, 1.

42. Andrade, M. F.; Zaratti, F.; Revista Boliviana de Física 2007, 13, 11.

43. Balderrama Flores, F. A.; Revista Metalúrgica 2012, 31, 5.

44. Pozo, J. I.; Crespo, M. Á. G. Em A solução de problemas em ciências da natureza; Pozo, J. I., ed.; Artmed: Porto Alegre, 1998.

45. Passos, C. G.; Del Pino, J. C.; Quim. Nova 2017, 40, 219.

46. Vasconcellos, C. S.; Planejamento: Projeto de Ensino-Aprendizagem e Projeto Político-Pedagógico, Libertad: São Paulo, 2008.

47. Luxford, C. J.; Bretz, S. L.; J. Chem. Educ. 2014, 91, 312. 